\title{
Social and strategic ambiguity versus betrayal aversion
}

\author{
Chen $\mathrm{Li}^{\mathrm{a}}$, Uyanga Turmunkh ${ }^{\mathrm{b}, \mathrm{c}}$, Peter P. Wakker ${ }^{\mathrm{a}, *}$ \\ a Erasmus School of Economics, Erasmus University Rotterdam, P.O. Box 1738, 3000 DR Rotterdam, the Netherlands \\ ${ }^{\mathrm{b}}$ Department of Economics and Quantitative Methods, IESEG School of Management, 3 Rue de la Digue, 59000 Lille, France \\ c LEM-CNRS 9221, France
}

\section{A R T I C L E I N F O}

Article history:

Received 9 June 2019

Available online 28 July 2020

\section{JEL classification:}

$\mathrm{C} 72$

D91

C81

Keywords:

Social ambiguity

Betrayal aversion

Trust

Strategic uncertainty

\begin{abstract}
A B S T R A C T
This paper examines the difference between strategic ambiguity as in game theory and ambiguity arising in individual decisions. We identify a new, non-strategic component underlying all strategic ambiguities, called social ambiguity. We recommend controlling for it to better identify strategic causes. Thus, we shed new light on Bohnet and Zeckhauser's betrayal aversion in the trust game. We first show theoretically that, contrary to preceding claims in the literature, ambiguity attitudes can play a role here. We then show experimentally that social ambiguity, rather than betrayal aversion, can explain our empirical findings. Using our new control, we identify the unique effect of strategic ambiguity. Strategic complexity increases ambiguity perception and thus increases people's likelihood insensitivity when making decisions under strategic ambiguity. Our results show the usefulness of controlling for ambiguity attitudes before speculating on strategic factors.
\end{abstract}

(C) 2020 Elsevier Inc. All rights reserved.

\section{Introduction}

Ambiguity (unknown probabilities) plays a role in many social interactions because there is usually uncertainty about decisions of others and probabilities of others' decisions are rarely available. Traditionally, game theorists have made the idealized but empirically unrealistic assumption that probabilities can be assigned to all uncertainties. Tractable and widely accepted ambiguity theories were not available when the foundations of game theory were developed. Such ambiguity theories only became available later (surveyed by Marinacci, 2015), and several theoretical papers subsequently applied ambiguity theories to game theory (surveyed by Evren, 2019 p. 287 and Kellner and le Quement, 2017 p. 272). Empirical studies began to appear only recently. These include Calford (2020), Chark and Chew (2015), Dominiak and Duersch (2019), Eichberger and Kelsey (2011), Ivanov (2011), and Kelsey and le Roux (2015, 2018).

Traditionally, ambiguity attitudes were measured using artificial events such as Ellsberg urns with compositions kept secret or experimenter-specified probability intervals where the exact probability was kept secret. For individual decisions, Baillon et al. (2018) introduced a method that can measure ambiguity attitudes for general events, so that applicationrelevant events can be used, increasing external validity and subjects' motivations. Li et al. (2019) extended this method to game theory and applied it to trust games. They showed empirically that ambiguity attitudes play a role there and that ambiguity aversion reduces trust. We use their method in our experiment.

\footnotetext{
* Corresponding author.

E-mail addresses: c.li@ese.eur.nl (C. Li), u.turmunkh@ieseg.fr (U. Turmunkh), wakker@ese.eur.nl (P.P. Wakker).
} 
A feature typical of game theory is that other players, unlike nature, interact consciously with the decision maker, having common or opposite interests. That is, we deal with strategic uncertainty. ${ }^{1}$ This paper identifies a new, non-strategic, component underlying all strategic ambiguities, which we call social ambiguity. People treat acts by humans, also in the absence of strategic interactions, differently than acts of nature, which do not involve human agency and free will. Even if game theory plays no role, then the psychological theory of mind still distinguishes social from nature uncertainty (Kets and Sandroni, 2019). For example, deliberate minds can benefit from taking each other's perspective. The presence of deliberate, teleological actions is what distinguishes the social from the natural sciences (Veblen, 1909), also beyond game theory.

The question now arises to what extent phenomena ascribed to the strategic aspects of a game might have been driven by general non-strategic social ambiguity. We investigate this question for a well-known case: the betrayal aversion game of Bohnet and Zeckhauser (2004) and Bohnet et al. (2008). Henceforth, BZ refers to these two papers. Investigations of this question for other games are left as a topic for future research, where nature and social treatments can be added as in our experiment.

BZ developed a clever design using minimally acceptable probabilities (MAPs) to measure betrayal aversion in the trust game while correcting for risk attitude. They provided a theoretical analysis claiming that ambiguity attitudes cannot play any role in their experiment, and subsequently focused on risk attitudes. It led to the conclusion that betrayal aversion drives their results. However, BZ's theoretical analysis was from a normative perspective, assuming Bayesian principles of dynamic optimization. To understand their data we should instead use a descriptive perspective. Descriptively, the aforementioned Bayesian principles are widely violated, and several authors have even argued for abandoning them normatively (references in §2). Using modern and empirically realistic ambiguity theories and their corresponding dynamic decision principles, we first show theoretically that ambiguity attitudes can very well play a role in BZ's MAP measurements. An example then shows that ambiguity attitudes with reasonable assumptions about beliefs can give rise to BZ's empirical findings without there being any betrayal aversion. Ambiguity is one of the confounds that affect MAP measurements, making it difficult to draw clear conclusions from them.

We then test betrayal aversion in an experiment. To control for ambiguity and analyze it, we use Li et al.'s (2019) method instead of BZ's MAPs. We find no betrayal aversion. This is consistent with other studies that did not find it either (references in §6). We also measure social ambiguity and find that this, rather than betrayal aversion, impacts motivational (aversion/seeking) behavior in trust games. ${ }^{2}$

Whereas ambiguity about betrayal does not affect behavior motivationally, it does affect behavior cognitively, by increasing insensitivity. ${ }^{3}$ That is, people are extra insensitive to (differences in) likelihoods of others' trustworthiness. Apparently, strategic ambiguity is not more aversive, but is harder to process, than non-strategic (social or nature) ambiguity. This implies that people prefer to gamble on nature rather than on others' trustworthiness when good outcomes are likely, but prefer to gamble on trustworthiness rather than on nature when good outcomes are unlikely.

The paper proceeds as follows. Section 2 provides a theoretical analysis, showing that ambiguity does play a role in BZ's betrayal aversion game, and motivating the ensuing experimental investigation. Our empirical measurement of ambiguity attitudes is explained in $\S 3$, and the experiment is in $\S 4$. To parse out social versus strategic ambiguity in games and, hence, to identify what is truly caused by strategic interactions, our experiment includes the following three treatments: nature ambiguity, social ambiguity without (strategic) betrayal or special other emotions involved, and strategic social ambiguity with betrayal involved. The data and findings are in $\S 5$ and are discussed in $\S 6$. Section 7 concludes. The appendix proves some claims of $\S 2$ by providing numerical examples.

\section{Dynamic models for the trust game, with and without ambiguity}

Our experiment concerns the two-player trust game in Fig. 1. Throughout, $(€ \alpha, € \beta)$ denotes an outcome where the 1st mover (the trustor) receives $€ \alpha$ and the 2 nd mover (the trustee) $€ \beta$. The 1 st mover will choose the certain outcome of Distrust if she considers it likely that the 2nd mover chooses the selfish act $C$.

BZ considered the above game but without act $B$ and this is how we analyze the game in this section. (We will use $B$ later, for reasons explained later.) In BZ's betrayal aversion game, each subject was first asked whether she would be trustworthy (go for $(15,15)$ ) if given the chance, without any other information. That is, subjects played the trust game here as 2nd mover. It was measured which fraction, denoted $p^{*}$, of the subjects in the sample chose to be trustworthy. This then served as input in the following procedure.

\footnotetext{
${ }^{1}$ Discussions of the differences between nature and strategic uncertainty include Aumann and Drèze (2009), Gilboa and Schmeidler (2003), Harsanyi (1982), Heinemann et al. (2009), Kugler et al. (2012), Nagel et al. (2018), Schneeweiss (1973), Sugden (1991 §XI, p. 782 bottom), and von Neumann and Morgenstern (1944 p. 11, p. 99).

2 Di Mauro and Castro (2011) used a similar line of reasoning and concluded that findings in voluntary contribution mechanism games, explained before by other regarding preferences, may instead have been due to ambiguity aversion.

${ }^{3}$ Insensitivity implies that beliefs are all moved in the direction of fifty-fifty, with decreased discriminatory power for intermediate changes of likelihood. For risk, it leads to inverse-S probability weighting. For ambiguity, it is usually more pronounced than for risk (Trautmann and van de Kuilen, 2015). Insensitivity is an additional, cognitive, component orthogonal to the motivational aversion/seeking component, for both risk and ambiguity.
} 


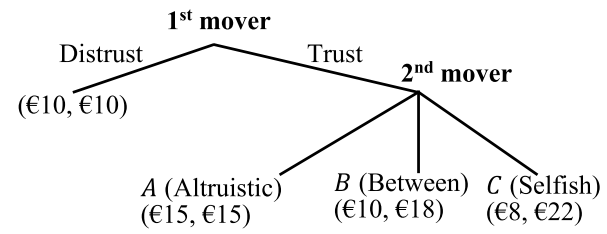

Fig. 1. Trust game.

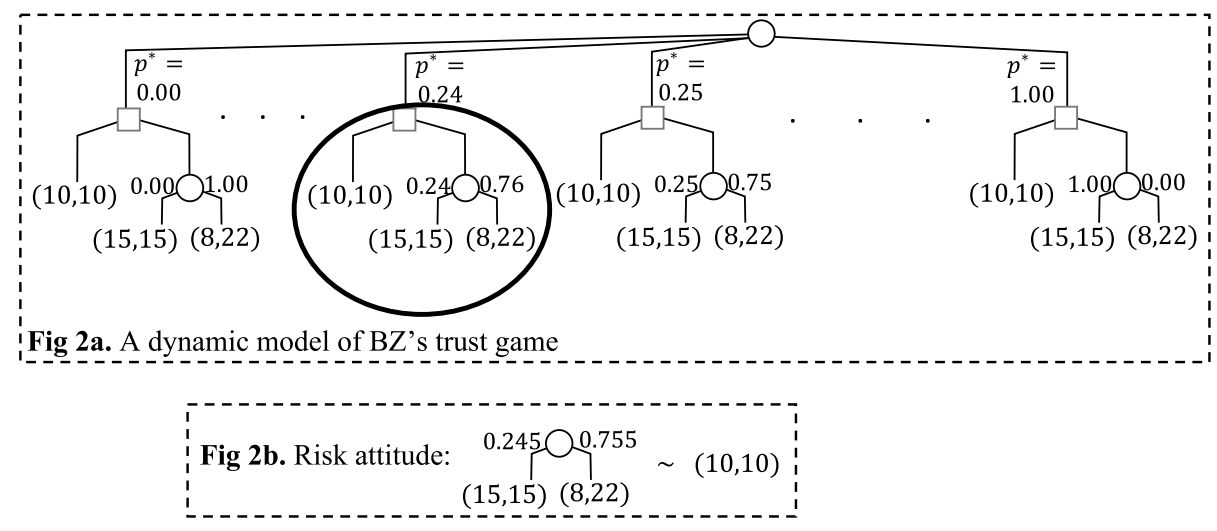

Fig. 2. BZ's model for ruling out ambiguity.

As for the role of 1 st mover, subjects were asked, before being informed about the value of $p^{*}$, to specify a minimally acceptable probability (MAP) through the following question, where the italicized words between braces have been added here:

How large would the probability $p$ of being paired with Person $\mathrm{Y}$ [an agent] \{2nd mover\} who chose Option 1 [to be trustworthy] \{Altruistic $\}$ minimally have to be for you to pick Alternative B [the lottery] \{Trust \} over Alternative A [the sure thing] \{Distrust $\}$ ?

If $M A P \leq p^{*}$, then the subject played the role of 1 st mover who chose Trust. She was matched with a randomly chosen other subject from the sample and received the outcome resulting from the other's choice as 2nd mover in the game. Bohnet et al. (2008 p. 297) wrote: "She thus had a $p^{*}$-chance of receiving the good outcome." If $M A P>p^{*}$, then the subject played the role of 1 st mover who chose Distrust, and the sure outcome $(10,10)$ resulted. Bohnet et al. (2008 p. 298$)$ wrote about this MAP measurement:

This mechanism is incentive compatible: a rational principal should be indifferent between the sure thing and the gamble with her reported MAP, since individuals cannot affect the probability they receive in the lottery. Given our procedure, assuming that a principal adheres to the Substitution Axiom of von Neumann-Morgenstern utility, truth-telling is a dominant strategy. .... Note that the value of $\mathrm{p}^{*}$ in the trust game may have been thought to be more (or less) uncertainambiguous in the terminology related to the Ellsberg Paradox (Daniel Ellsberg, 1961) ... But this should have no effect on the principal's reported MAP. A MAP is a cutoff value relating to preferences, and the estimated value of $\mathrm{p}^{*}$ should not affect it; i.e., the procedure is incentive compatible even when principals are ambiguity averse. [Italics added]

Fig. 2a presents a dynamic picture of BZ's reasoning, which we explain in some detail before discussing it. First, in the upper circle, the value $p^{*}$ (ranging from $0.00,0.01, \ldots$, to 1.00 ) is determined. Next, at the resulting square, conditioned on the value of $p^{*}$, the subject's 1st mover choice between left (Distrust; safe) and right (Trust; risky) is implemented. Note that this can be taken as a risky decision only after having conditioned on $p^{*}$. A restriction in this game is that the subject, if choosing right conditional on some probability $p^{*}$, must also do so for all higher probabilities $p^{*}$. That is, the subject has to choose a MAP and then choose right for all $p^{*} \geq M A P$ and left for all $p^{*}<M A P$. Subjects will want to satisfy this restriction anyhow, so that it is no real restriction. Finally, in the case of Trust, the other player's (2nd mover) choice is implemented in the lower circle.

Fig. $2 \mathrm{~b}$ depicts an assumed indifference regarding risk attitude. The encircled subtree in Fig. $2 \mathrm{a}$, for $p^{*}=0.24$, has a less favorable risky act than in Fig. $2 \mathrm{~b}$, so that here a left (Distrust) choice follows. It also does at all subtrees to the left. In all subtrees to the right, a right (Trust) decision follows. MAP is 0.25 , or more precisely, 0.245 . The risk attitude in Fig. $2 \mathrm{~b}$ completely determines the behavior of the subject in the trust game, and her ambiguity attitude plays no role. This was BZ's reasoning, because of which they ignored ambiguity attitudes in the rest of their paper. 


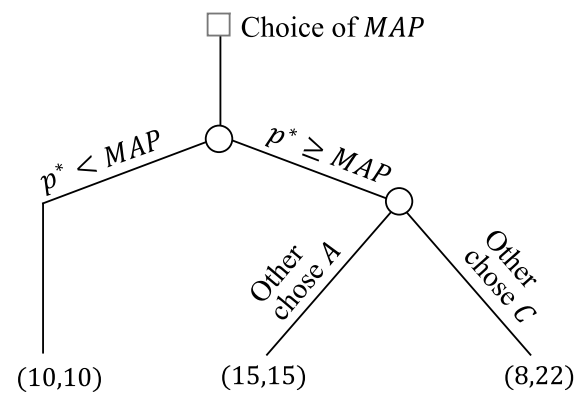

Fig. 3. An alternative dynamic model of BZ's betrayal aversion game.

A difficulty with BZ's reasoning is that it is normative; see the words in italics in their citation above. BZ's reasoning holds for rational expected utility maximizers. In particular, it requires that the encircled decision in the subtree in Fig. 2a is evaluated irrespectively of what goes on in the other subtrees. We call this requirement consequentialism. Other terms used in the literature include isolation and separability, and the requirement is part of backward induction. The relevant question here is descriptive, though. Will the reasoning hold for most subjects in BZ's or our experiments, and will it hold for most human beings?

At the end of the 1980s, it became widely understood that consequentialism, together with two even more seemingly innocuous and self-evident dynamic decision principles (dynamic consistency and reduction of compound lotteries ${ }^{4}$ ) have a strong implication for static decisions: they imply expected utility (Machina, 1989). Burks (1977 Ch. 5) and Kahneman and Tversky (1979; pseudo-certainty) had argued this earlier. Thus, everyone deviating from expected utility, including all people who are not ambiguity neutral (most subjects in experiments, and most human beings in general), violate at least one of these principles. Papers that tested these conditions jointly, finding them violated to various degrees, include Cohen et al. (2000), Cubitt et al. (1998), and Dominiak et al. (2012). Many empirical violations of consequentialism have been found, ${ }^{5}$ with some more cited later. Ellis (2018) provides recent discussions of the principles and analyzes their implications for game theory. They are also central in Battigalli et al. (2019).

For situations with many different outcomes, consequentialism and backward induction may be most tractable, and may therefore be psychologically plausible. However, with relatively few different outcomes and many event branches, forwardinduction type reasoning and dynamic consistency are more plausible (Amos Tversky 1993, personal communication). It is then easier for subjects to focus on each separate outcome and the event (set of paths) leading to it, as in Fig. 3, than on the many subevents with many certainty-equivalent substitutions to be carried out, as in Fig. 2. This is the case for BZ's experiment. It provides a first reason why we think that Fig. 3 better captures subjects' perception. Some authors even argued for abandoning consequentialism normatively (Machina, 1989; McClennen, 1990; suggested by Ellis, 2018).

Unlike Fig. 2, Fig. 3 positions the resolution of uncertainty about $p^{*}$ after a MAP choice, as it is temporally experienced by the subjects. They are informed about $p^{*}$ only after determining their MAP. They do not choose their MAP conditionally on $p^{*}$, but, the other way around, they are informed about $p^{*}$ conditionally upon (after) their MAP choice. ${ }^{6}$ This is a second reason why we conjecture that most subjects perceive BZ's game as in Fig. 3, and why few subjects and also few researchers perceive the case as in Fig. 2 upon first reading the BZ trust game.

Under classical rational theories, a researcher is free to use Fig. 2 or 3, or whichever other dynamic model is most convenient, and apply backward induction at will, because all such analyses give the same result. This consistency is lost once we give up expected utility and adopt ambiguity theories. Then we have to deliberately choose between Fig. 2 and 3 (and possibly other candidates).

If a researcher decides to use Fig. 2 to analyze the game, then she must reckon with massive violations of consequentialism. The decision in the encircled subgame will be strongly affected by what happens in the other subgames. Such global effects are typical of nonexpected utility. They are enhanced because most subjects never perceive Fig. 2 and, for instance, never perceive the encircled subgame in Fig. 2 in isolation. They perceive these subgames holistically, joined, as in Fig. 3.

All events in Fig. 3 are ambiguous, and their uncertainty is complex, involving $p^{*}$. Therefore, ambiguity attitudes, complexity, different beliefs, and dynamic optimization all play a role in subjects' choices of MAP, and it is not easy to tease

\footnotetext{
4 This is the condition for decision under risk. Ghirardato (2002) presented its analog for uncertainty, which amounts to collapsing consecutive events. Essentially the same conditions occur in intertemporal choice (Halevy, 2015).

5 In the Anscombe-Aumann (1963) framework of ambiguity, this condition received the misleading name monotonicity. Skiadas (2013 p. 63) pointed out: "This is not an innocuous assumption." Many theoretical studies of individual choice criticized the condition on both normative and descriptive grounds. See Bade (2015), Bommier (2017), Ghirardato (2002), Hammond (1988), Holt (1986), Karni and Safra (1987), Machina (1989, 2014 p. 385 3rd bulleted point), Wakker, 2010 (Fig. 10.7.1). Empirical tests in individual choice falsifying it include Baltussen et al. (2012), Cox et al. (2015), and Schneider and Schonger (2018). Isolation has also been criticized in discussions of the random incentive system, where any spillover or learning effect entails a violation, and in the context of nonneutrality towards the timing of the resolution of uncertainty. We will not cite the extensive literature on these topics.

6 In game theory's terminology, the MAP measurement is a strategy method. This can differ from posterior choice as in Fig. 2 (Bardsley et al., 2010 §6.3; Brosig et al., 2003; Güth et al., 2001).
} 


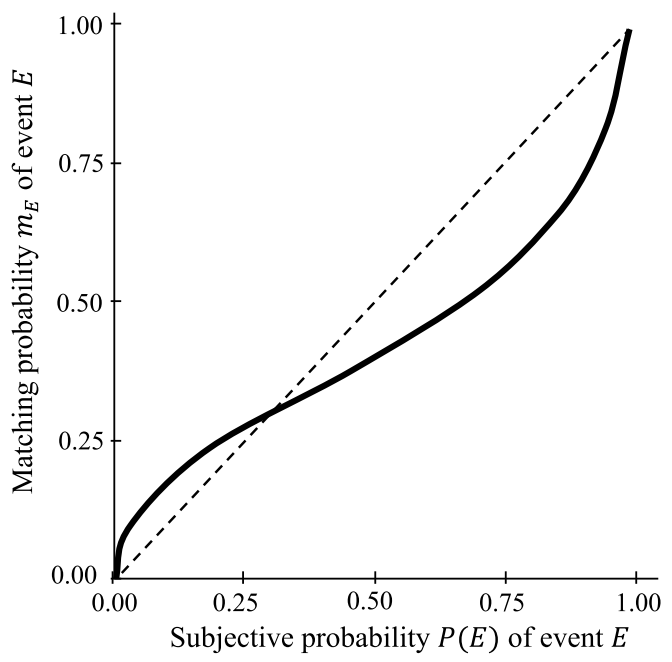

Fig. 4. Commonly observed matching probabilities.

them apart. Normatively speaking, subjects' beliefs about receiving each outcome should not affect their choice of MAP, assuming separability of SEU, because then Fig. 3 is equivalent to Fig. 2. However, descriptively this is unlikely to be the case. The appendix gives numerical examples to show how ambiguity can impact reported MAPs and lead to BZ's findings without requiring people to be betrayal averse.

Many researchers consider deviations from expected utility and nonneutral ambiguity attitudes to be rational (CerreiaVioglio et al., 2011; Ellsberg, 1961; Gilboa and Schmeidler, 1989; Klibanoff et al., 2005). Then it is even rational for players to let nonneutral ambiguity attitudes play a role in the trust game.

The theoretical arguments advanced here demonstrate that ambiguity can play a role in MAPs and the resulting findings on the other versus nature divide reported by BZ. The rest of the paper investigates the role of ambiguity in the trust game empirically. The MAP design does not allow for a clear separation of the impact of multiple factors, including ambiguity, and more elaborate measurements would be needed before we can interpret results from that design. We therefore adopt an alternative design to investigate the impact of ambiguity on the other versus nature divide while controlling for other factors. We then find no role for betrayal aversion in the trust game.

\section{Measuring ambiguity attitudes}

Consider the two-player trust game in Fig. 1, now with the act $B$ included. We first describe how appropriately constructed side bets, using matching probabilities, can be used to measure the ambiguity attitude of the 1st mover while avoiding income effects (Costa-Gomes et al., 2014 footnote 6; Heinemann et al., 2009 pp. 189-190). A decision maker's matching probability of an event $E$ is the probability $m_{E}$ such that

$$
(E: x) \sim\left(m_{E}: x\right)
$$

That is, it makes the decision maker indifferent between the ambiguous lottery $(E: x)$ offering prize $x$ if event $E$ occurs and nothing otherwise, and the risky lottery $\left(m_{E}: x\right)$ offering the (same) prize $x$ with probability $m_{E}$ and nothing otherwise. Under Savage's (1954) subjective expected utility (SEU)-thus, ambiguity neutrality-the ambiguous lottery ( $E: x)$ is evaluated by its SEU, $P(E) U(x)+(1-P(E)) U(0)$, with $P(E)$ the decision maker's subjective probability of event $E$ and $U$ her utility function. The risky lottery $\left(m_{E}: x\right)$ is evaluated by $m_{E} U(x)+\left(1-m_{E}\right) U(0)$. The matching probability $m_{E}$ of an ambiguity-neutral decision maker then measures her subjective probability: $m_{E}=P(E)$. Then $m_{E}$, taken as a function of $E$, satisfies the laws of probability. For example, then, with $E^{c}$ denoting complementary event, $m_{E}+m_{E^{c}}=1$. Empirically, we usually find $m_{E} \neq P(E)$, because most people are not ambiguity neutral. The size and sign of the deviations from the laws of probability reflect ambiguity attitude. For example, under ambiguity aversion we have $m_{E}+m_{E^{c}}<1$.

Fig. 4 shows a graph of the commonly observed deviations of matching probabilities from subjective (ambiguity-neutral; see §7) probabilities, assuming for simplicity that the latter can be specified. The dotted line in the figure represents the matching probabilities of an ambiguity-neutral decision maker, who treats unknown (subjective) probabilities as if they were known. Empirical studies have found that people commonly behave as represented by the solid line (Evren, 2019 p. 286; l'Haridon et al., 2018; Trautmann and van de Kuilen, 2015; Wakker, 2010 \$10.4.2), displaying ambiguity aversion for likely events and ambiguity seeking for unlikely events. The commonly observed ambiguity attitude described by the solid line captures the well-known Ellsberg paradox. For example, in Ellsberg's two-color urn problem, people prefer, regardless 
of the winning color, to gamble on the known urn with equal numbers of green ${ }^{7}$ and red balls over the unknown urn. Such preferences can be accommodated by any matching probability function (including the one depicted in Fig. 4) with $m_{E}<0.5$ for event $E$ whose subjective probability $P(E)=0.5^{8}$

The relative elevation of the matching probability function captures the extent to which the decision maker likes or dislikes ambiguity (motivational component; ambiguity aversion or seeking), and the relative flatness in the middle captures the (in)sensitivity of the decision maker, who insufficiently discriminates different intermediate levels of likelihood of ambiguous events (cognitive component). We call the cognitive component ambiguity-generated likelihood insensitivity, or a-insensitivity for short. ${ }^{9}$

For measuring ambiguity attitudes in a game against others, a major challenge is the difficulty of controlling for the decision maker's subjective probabilities. Baillon et al. (2018) proposed a method that overcomes this challenge. They showed that matching probabilities of three events, constituting a partition of the state space, and their unions are sufficient for quantifying the decision maker's ambiguity aversion and a-insensitivity, irrespective of subjective probabilities/beliefs. In the trust game of Fig. 1, it is therefore sufficient to elicit the 1st mover's matching probabilities $m_{A}, m_{B}$, and $m_{C}$ of the three single events $A, B$, and $C$ corresponding to the three possible acts of the 2nd mover, together with the matching probabilities $m_{A B}, m_{A C}$, and $m_{B C}$ of the three composite events ( $A$ or $\left.B\right),(A$ or $C$ ), and ( $B$ or $C$ ). For a detailed discussion of how such ambiguity attitudes can be measured in strategic games without disturbing the game, see Li et al. (2019). For analyses using traditional ambiguity-neutral beliefs, see Perea (2012).

Baillon et al. (2018) proposed the following two indices to quantify ambiguity aversion ( $b$ ) and a-insensitivity ( $a$ ):

$$
\begin{aligned}
& b=1-\left(m_{s}+m_{c}\right), \\
& a=3 \times\left(\frac{1}{3}-\left(m_{c}-m_{s}\right)\right) .
\end{aligned}
$$

Here $m_{s}=\left(m_{A}+m_{B}+m_{C}\right) / 3$ denotes the average single-event matching probability, and $m_{C}=\left(m_{A B}+m_{A C}+m_{B C}\right) / 3$ denotes the average composite-event matching probability. Intuitively, the ambiguity aversion index $b$ captures the general elevation of the decision maker's matching probabilities, using the sum $m_{s}+m_{c}$ which, under ambiguity-neutrality, equals 1 so that $b=0$. The a-insensitivity index $a$ captures the flatness of the matching probability function in the middle region, using the difference $m_{c}-m_{s}$ which, under ambiguity-neutrality, equals $1 / 3$ so that $a=0$. Positive values of $b$ and $a$ describe ambiguity-aversion and a-insensitivity. The larger these values, the more the decision maker deviates from ambiguity-neutrality.

\section{Experiment}

\section{Subjects.}

$\mathrm{N}=248$ students from Erasmus University Rotterdam took part in the experiment. On average, the experimental session lasted 45 minutes and a subject earned $€ 14.68$. $^{10}$

\section{Treatments.}

The experiment was computerized and involved three between-subject treatments-nature, social, and betrayalcorresponding to the three different types of ambiguity that subjects faced. Experimental instructions are in Online Appendix A. $\mathrm{N}_{1}=88, \mathrm{~N}_{2}=80$, and $\mathrm{N}_{3}=80$ subjects were randomly assigned to nature, social, and betrayal ambiguity, respectively. In each treatment, a subject faced a triple of mutually exclusive and exhaustive events $A, B$, and $C$, only one of which was true. Subjects did not learn the true event until the end of the experiment.

In the nature ambiguity treatment, ambiguity was generated by the hidden marking of a card drawn by each subject at the start of the experiment. The card was drawn from a deck of four cards. The subjects were informed that each card could be marked with the letter $A, B$, or $C$, but they did not know how many of the cards in the deck were marked with each of the three letters. Any composition was possible.

Subjects in the other two treatments faced social ambiguity. They were randomly assigned an anonymous partner (a fellow subject) at the start of the experiment. The events $A, B$, or $C$ described the choice made by the partner. As in nature ambiguity, the ambiguity facing the subjects was presented to them at the start of the experiment, and resolved at the end. Subjects assigned to social ambiguity (without betrayal) were told that the assigned partner would choose one of three

\footnotetext{
7 We avoid Ellsberg's black color because the symbol $B$ is used for another purpose.

8 Let $G$ and $R$ denote the events that a green ball and a red ball is drawn, respectively, from the unknown urn. Chew and Sagi (2008) showed that the events can have subjective probabilities $P(G)=P(R)=0.5$, but still the decision maker's matching probabilities $m_{G}$ and $m_{R}$ of the two events can both be less than $0.5-$ i.e., $(G: x) \sim\left(m_{G}: x\right)$, $(R: x) \sim\left(m_{R}: x\right)$, and $m_{G}, m_{G}<0.5-$ then $(G: x) \prec(0.5: x)$ and $(R: x) \prec(0.5: x)$. This shows that, contrary to what has long been believed, the Ellsberg paradox can be reconciled with subjective probabilities.

9 Gonzalez and Wu (1999) provide a clear discussion of these psychological interpretations of elevation and curvature for risk attitudes. Their concepts are naturally extended to other weighting functions (Wakker, 2010 \$10.4), being matching probabilities in our case. Gayer (2010) gives theoretical justifications.

$10 \mathrm{Li}$ et al. (2019) analyzed the trust game. Their dataset included 80 observations from this sample corresponding to one (betrayal) treatment, as well as additional observations collected separately.
} 


\begin{tabular}{|c|c|c|c|}
\hline $\begin{array}{l}\text { Ambiguity } \\
\text { Treatment }\end{array}$ & Nature & Social & Betrayal \\
\hline Step 1. & \multicolumn{3}{|c|}{ General instructions } \\
\hline $\begin{array}{l}\text { Step } 2 . \\
\text { Presentation of } \\
\text { ambiguity }\end{array}$ & $\begin{array}{l}\text { Subjects drew a } \\
\text { card from an } \\
\text { ambiguous deck } \\
\text { of four cards. } \\
\text { It was } \\
\text { ambiguous } \\
\text { whether the card } \\
\text { drawn was } \\
\text { marked with } \\
\text { letter } A, B \text {, or } C \text {. }\end{array}$ & $\begin{array}{l}\text { Subjects were } \\
\text { informed that they } \\
\text { were matched with a } \\
\text { partner, and told that } \\
\text { the partner would } \\
\text { choose one desired } \\
\text { snack out of three: a } \\
\text { salty snack, a dried } \\
\text { fruit snack, and a } \\
\text { chocolate bar, } \\
\text { labeled } A, B \text {, or } C \text {. } \\
\text { It was ambiguous } \\
\text { whether the partner } \\
\text { would choose snack } \\
A, B \text {, or } C \text {. }\end{array}$ & $\begin{array}{l}\text { Subjects were informed } \\
\text { that they were matched } \\
\text { with a partner, and told } \\
\text { that the partner would } \\
\text { choose one of three } \\
\text { allocations: }(€ 15, € 15) \text {, } \\
(€ 10, € 18) \text {, or }(€ 8, € 22) \text {, } \\
\text { labeled } A, B, \text { or } C \text {. } \\
\text { Subjects could choose a } \\
\text { safe allocation of }(€ 10 \text {, } \\
€ 10) \text { or let the partner's } \\
\text { choice determine the } \\
\text { allocation. } \\
\text { It was ambiguous } \\
\text { whether the partner } \\
\text { would choose allocation } \\
A, B, \text { or } C \text {. }\end{array}$ \\
\hline
\end{tabular}

\begin{tabular}{|l|l|}
\hline & \\
$\begin{array}{l}\text { Step 3. } \\
\text { Measurement } \\
\text { of ambiguity } \\
\text { attitude }\end{array}$ & $\begin{array}{l}\text { Elicitation of matching probabilities of the six events } A, B, C,(A \text { or } C), \text { and }(B \text { or } C) . \\
\end{array}$ \\
\hline
\end{tabular}

Step 4.

Ambiguitygenerating

choice as a partner to another subject
Subjects made an ambiguity-generating choice for a subject in the social or betrayal treatment Subjects either chose one desired snack out of three: a salty snack, a dried fruit snack, and a chocolate bar, labeled $A, B$, and $C$; or subjects chose one of three allocations: $(€ 15, € 15),(€ 10$, $€ 18)$, and $(€ 8, € 22)$, labeled $A, B$, and $C$.

Fig. 5. Summary of experimental procedure.

snacks labeled $A, B$, and $C$. The partner's choice involved no betrayal, only the consideration of which of the three snacks would be most desirable to her. In the third treatment, subjects faced betrayal ambiguity. Here, subjects were presented with the description of the game and were told that the partner would choose one of the three allocations labeled $A, B$, and $C$ in the trust game (Fig. 1). ${ }^{11}$ The partners made this choice prior to being informed about whether or not the subject chose Trust or Distrust, so that the partner's choice between $A, B$, and $C$ had also been specified after the subject's choice of Distrust.

\section{Procedure.}

Fig. 5 presents the procedure for the three treatments. In step 1, subjects were given general instructions, common for all three treatments. In step 2, the treatment-specific ambiguity was presented. Subjects in the social and betrayal ambiguity treatments were informed that they were matched with a partner. In step 3, six matching probabilities were elicited from each subject, with the contingency events of the ambiguous lotteries varying in accordance with the subject's ambiguity treatment. Finally, in step 4 subjects in the social and betrayal ambiguity treatments selected one snack or one allocation in the role of a 2nd mover, generating ambiguity for their partners. Further details on the pairings of subjects are at the end of Online Appendix A.

\section{Matching probabilities and incentives.}

Matching probabilities were elicited as follows. In all three treatments, subjects faced a triple $\{A, B, C\}$ of mutually exclusive and exhaustive ambiguous events. We elicited the following six indifferences from each subject:

\footnotetext{
11 We did not use the terms trust/distrust and altruistic/between/selfish for the subjects in the experiment, but only the neutral letters as labels.
} 


$$
\begin{aligned}
& (A: € 15) \sim\left(m_{A}: € 15\right), \\
& (B: € 15) \sim\left(m_{B}: € 15\right), \\
& (C: € 15) \sim\left(m_{C}: € 15\right), \\
& (A \text { or } B: € 15) \sim\left(m_{A B}: € 15\right), \\
& (A \text { or } C: € 15) \sim\left(m_{A C}: € 15\right), \\
& (B \text { or } C: € 15) \sim\left(m_{B C}: € 15\right) .
\end{aligned}
$$

All indifferences were elicited by means of bisection. That is, subjects were presented with a binary choice between an ambiguous lottery $(E: x)$ and a series of risky lotteries $(m: x)$, whose probability $m$ of winning the prize $x$ was adjusted with each subsequent step of the bisection until the matching probability $m$ was obtained such that $(m: x) \sim(E: x)$. We used a four-step bisection, and the binary choice in the first step used the risky lottery $(0.50: € 15)$. If a subject preferred the ambiguous lottery, the risky lottery was made more attractive in the second step. If the subject instead preferred the risky lottery, then she faced a choice between the ambiguous lottery and a less attractive risky lottery in the second step. Thus, the winning chance of the risky lottery was adjusted in each subsequent step, with the size of the adjustment shrinking at each subsequent step-from $+/-0.24$ to $+/-0.12$ and $+/-0.06$. Following the fourth choice, the matching probability could be inferred within $+/-0.03$ bounds.

Bisection has the practical advantage of being an efficient tool for measuring indifferences that is also easy for subjects to understand. However, the chained elicitation of bisection, if not carefully administered, can be problematic for real incentives. Specifically, in our elicitation of matching probabilities, which were adjusted according to previous choices of participants, one may be concerned about it being advantageous for participants not to answer according to their true preferences but instead to seek to improve the stimuli (risky prospects) that will occur in future choices, or to hedge. To avoid the possibility of such strategic behavior, we adopted the prior-incentive (Prince) system proposed by Johnson et al. (2020) in our experimental design.

Prince combines the spirit of the random-incentive system, in which only one of the experimental choice questions is implemented for real, with the added benefit of preventing subjects from answering strategically in adaptive experiments (where the sequence of stimuli presented to participants is path-dependent). The key element of Prince is that the choice question implemented for real is randomly selected prior to the experiment. In our experiment, the real choice question was provided to each participant at the start of the experiment in a sealed envelope, which the participant randomly selected from a box containing the envelopes. Thus, participants knew that they could not influence the choice question that was to be played for real. As explained before, also if a subject chose Distrust, then the partner's choices between $A, B, C$ were still made, and the corresponding matching probabilities were still incentivized.

\section{Data and findings}

All statistical tests in this paper are two-sided. Monotonicity tests of matching probabilities are in Online Appendix B. Figs. 6-8 present histograms of the six matching probabilities for the three sources of ambiguity. For nature ambiguity (Fig. 6), although subjects' matching probabilities are non-additive (due to ambiguity attitudes), they display the symmetry expected in an ambiguous situation where the decision maker has no reason to believe that one event is more likely than another event. In this case, subjects had no reason to believe that the card drawn was more likely to be marked with letter $A$ than with letter $B$ or letter $C$. The matching probabilities in Fig. 6 do not reject this for the single $(\mathrm{p}=0.11$; Friedman test) and composite events $(p=0.09$; Friedman test): the average matching probability was about 0.33 for each of the single events, and 0.60 for each of the composite events.

For social and betrayal ambiguities, symmetric beliefs were no longer plausible. Figs. 7 (social ambiguity) and 8 (betrayal ambiguity) confirm this. In both treatments, subjects tended to display a higher willingness to bet on one particular event: for both social and betrayal ambiguity, $\mathrm{p}<0.02$ in all Friedman tests comparing single (composite) event matching probabilities. For social ambiguity (Fig. 7), subjects were most willing to bet on event $C$ (partner chooses chocolate bar) (for both pairwise comparisons $\mathrm{p}<0.001$; Wilcoxon signed rank test). For betrayal ambiguity, subjects were most willing to bet on event $C$ (partner chooses selfish $C$ ) (for both pairwise comparisons $\mathrm{p}=0.01$; Wilcoxon signed rank test). The asymmetries exhibited by the subjects' matching probabilities were "reasonable" in the sense that the average matching probabilities (solid line) were close to the actual choice fractions of the partners (dotted line) for all events. ${ }^{12}$

The matching probabilities for social and betrayal ambiguities were more dispersed than those for nature ambiguity: (for all single events $\mathrm{p}<0.05$, for the composite events $\mathrm{p}=0.003,0.04$, and 0.36 (Brown-Forsythe test). There was clearly more heterogeneity in beliefs in social ambiguity than in nature ambiguity: for pairwise comparisons between social and nature ambiguities $\mathrm{p}<0.05$ for all single and two of three composite events; for pairwise comparisons between strategic and nature ambiguities $\mathrm{p}<0.05$ for two of three single events and one of three composite events (Brown-Forsythe test).

\footnotetext{
12 For nature ambiguity, the "reasonableness" of subjects' matching probabilities could be inferred from their symmetry. It was irrelevant whether their matching probabilities were close to the actually realized fractions or not. This is why we do not include dotted lines for nature ambiguity (Fig. 6).
} 


\section{Single events}
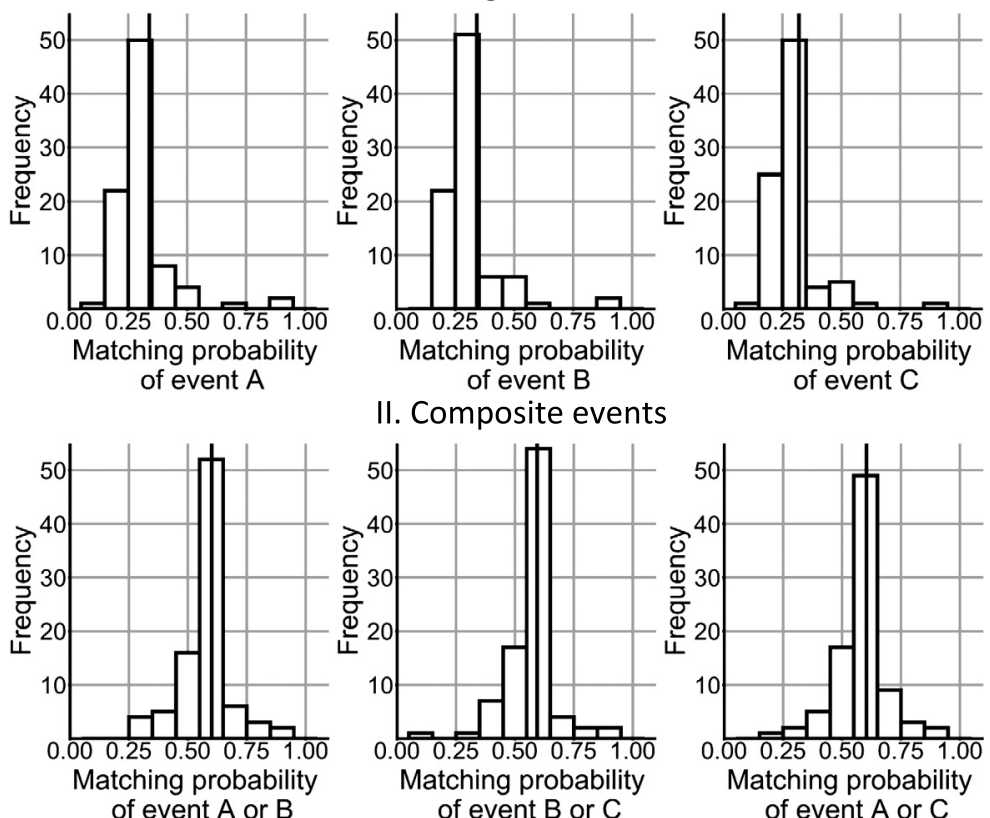

Note: Vertical solid line: the mean.

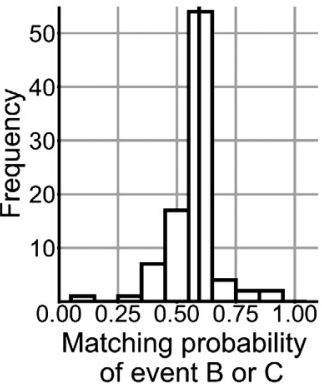

of event $\mathrm{A}$ or $\mathrm{C}$

Fig. 6. Histogram of matching probabilities for nature ambiguity.

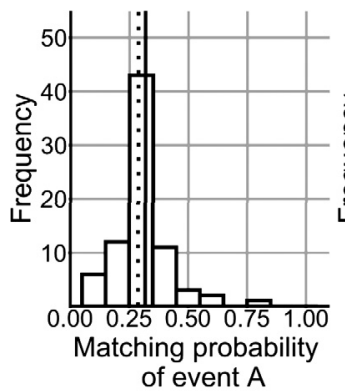

I. Single events
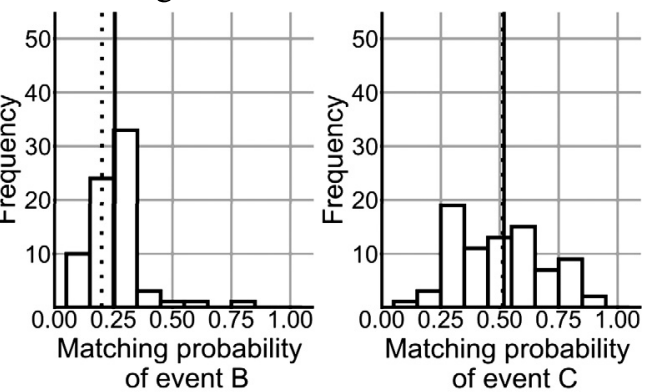

II. Composite events
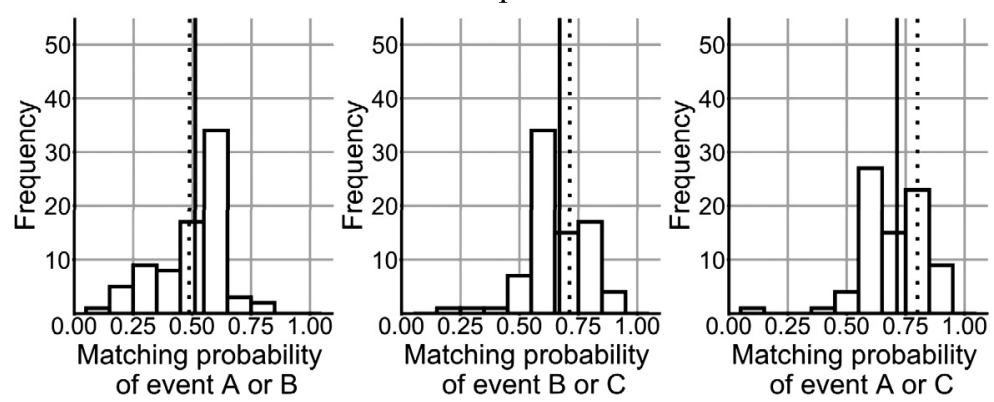

Note: Vertical solid line: mean. Dotted line: fraction of subjects choosing the event.

Fig. 7. Histogram of matching probabilities for social ambiguity.

Table 1 summarizes the distributions of subjects' ambiguity attitudes. The top panel shows the ambiguity aversion index. For nature ambiguity, we find ambiguity aversion $(b>0)$, consistent with the preceding literature that studied ambiguity attitudes using Ellsberg urns. However, there was no aversion toward social and betrayal ambiguities. Further, the bottom panel of the table shows that the more important component driving the deviation from ambiguity-neutrality was cognitive (a) rather than motivational $(b)$. A-insensitivity was significant $(a>0)$ for all ambiguities. 
I. Single events
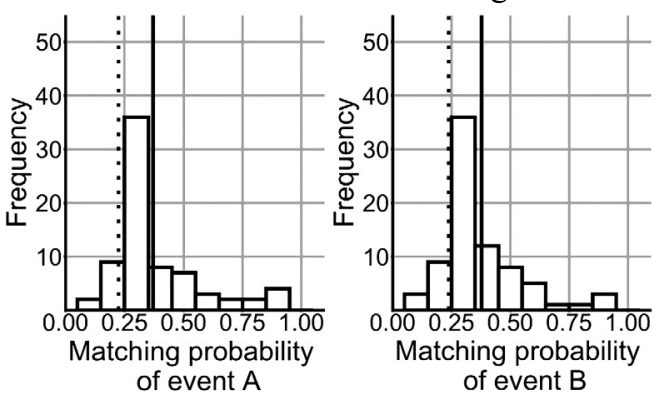

II. Composite events
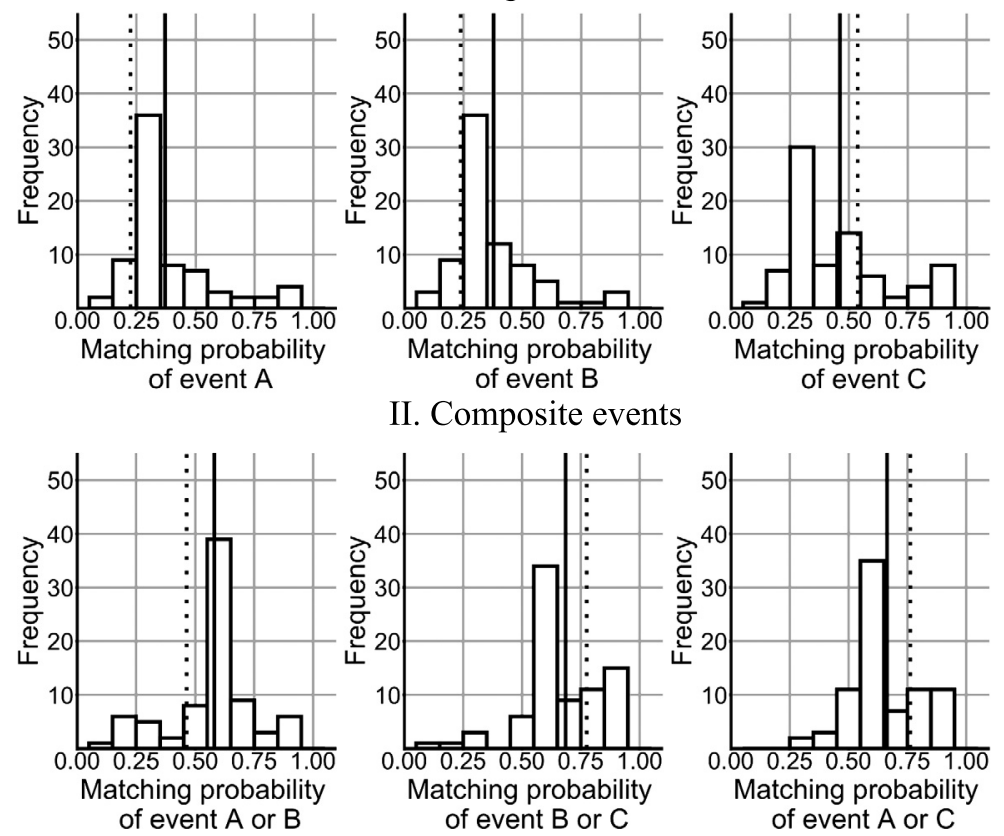

Note: Vertical solid line: mean. Dotted line: fraction of subjects choosing the event.

Fig. 8. Histogram of matching probabilities for betrayal ambiguity.

Table 1

Ambiguity attitudes by ambiguity treatment.

\begin{tabular}{lllll}
\multicolumn{2}{l}{ I. Ambiguity aversion index $(b)$} & & & \\
\hline Ambiguity treatment & Mean & Median & Interquartile range & $\begin{array}{l}\text { p-value } \\
\text { Wilcoxon tests } \\
b=0\end{array}$ \\
\hline Nature & & & & 0.00 \\
Social & 0.07 & 0.00 & {$[0.00,0.20]$} & 0.26 \\
Betrayal & 0.01 & 0.00 & {$[-0.04,0.06]$} & 0.30 \\
\hline
\end{tabular}

II. A-insensitivity index (a)

\begin{tabular}{lcccl}
\hline Ambiguity treatment & Mean & Median & Interquartile range & $\begin{array}{l}\text { p-value } \\
\text { Wilcoxon tests } \\
a=0\end{array}$ \\
\hline Nature & 0.20 & 0.10 & {$[0.10,0.34]$} & 0.00 \\
Social & 0.20 & 0.16 & {$[0.09,0.28]$} & 0.00 \\
Betrayal & 0.28 & 0.28 & {$[0.10,0.46]$} & 0.00 \\
\hline
\end{tabular}

Fig. 9 compares the ambiguity attitudes of nature versus social and betrayal. The left panel shows the differences in ambiguity aversion. Subjects were less ambiguity averse when the ambiguity concerned a partner's choice in a trust game (toward betrayal ambiguity) than when it concerned the marking of a card drawn from an unknown deck ( $<0.001$; MannWhitney test). Comparison of nature ambiguity with social ambiguity shows a similar difference, with subjects displaying less ambiguity aversion toward social ambiguity than toward nature ambiguity ( $\mathrm{p}=0.02$; Mann-Whitney test). When we compare social ambiguity with betrayal ambiguity, we find no difference in ambiguity aversion $(\mathrm{p}=0.16$; Mann-Whitney test). We thus do not find betrayal aversion. Instead, there is preference (rather than aversion) for social and betrayal ambiguity over nature ambiguity. The equal preference for social and betrayal ambiguity suggests that the motivational difference was driven by social ambiguity rather than by strategic ambiguity.

The right panel of Fig. 9 shows the differences in the cognitive component of ambiguity attitude, a-insensitivity. Subjects displayed a-insensitivity under all ambiguities (Table 1). They were more insensitive for betrayal than for social $(\mathrm{p}=0.03$; Mann-Whitney test) or nature ( $\mathrm{p}=0.01$; Mann-Whitney test) ambiguity. Social ambiguity played no role in the cognitive divide, as there was no difference in insensitivity between nature and social ambiguity ( $\mathrm{p}=0.65$; Mann-Whitney test). We conclude that, whereas social ambiguity affects the motivational divide in other versus nature ambiguity attitude, the presence of strategic complications in games against others leads to more a-insensitivity. Furthermore, stronger insensi- 
I. Ambiguity aversion index $(b)$

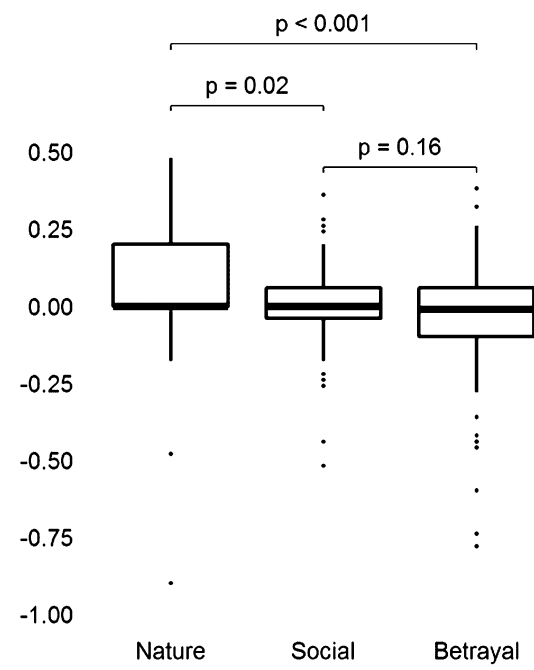

II. A-insensitivity index $(a)$

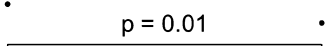

1.00

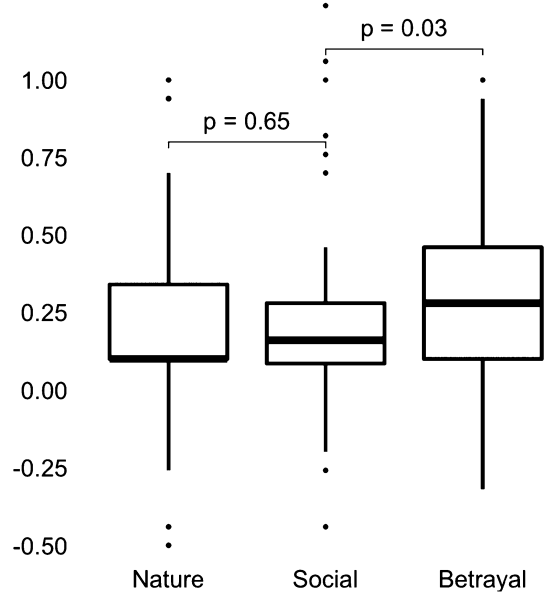

$-0.50$

Note: Box-and-whiskers plots of distributions of ambiguity aversion index (left panel) and a-insensitivity index (right panel) by ambiguity treatment. The box shows the interquartile range and the median (solid line) of each distribution. The whiskers show the lower and upper quartiles, excluding outliers. Outliersvalues larger than $(3 / 2)$ times the upper quartile or lower than $(3 / 2)$ times the lower quartile-are indicated by dots. All tests of differences are Mann-Whitney U tests.

Fig. 9. Differences in ambiguity attitudes.

tivity under betrayal ambiguity implies that people prefer betrayal ambiguity over nature ambiguity (betrayal-seeking) for small likelihoods of winning and prefer nature ambiguity over betrayal ambiguity (betrayal-averse) for larger likelihoods of winning.

\section{Discussion}

Li et al. (2019) analyzed the empirical role of ambiguity in the trust game. This paper adds the insights that come from identifying social ambiguity, in particular for BZ's betrayal aversion. We found that attitudes to ambiguity in strategic interactions with others are different from attitudes toward nature-generated ambiguity that is non-social and non-strategic. Ambiguity aversion, which has been found in many preceding empirical studies and which we also find for nature ambiguity, plays no role in strategic interactions. Our subjects exhibit no aversion to betrayal ambiguity. Nor did we find ambiguity aversion when subjects face social ambiguity without strategic complications. People are less averse toward ambiguity generated by other humans-regardless of strategic aspects-than non-social Ellsberg-like mechanisms. Papers confirming this include Bolton et al. (2016) and Chark and Chew (2015).

The competence hypothesis (Heath and Tversky, 1991) may help to explain our motivational findings: people do not dislike ambiguity if they feel competent about the source generating the ambiguity. Heath and Tversky (1991) found that people preferred to bet on ambiguous events rather than equiprobable chance events when they considered themselves knowledgeable, but not otherwise. Fox and Weber (2002) confirmed the competence effect in games, analyzed as choices under ambiguity. Studies comparing preferences between ambiguous events also find that people prefer the familiar over the unfamiliar source. For instance, they prefer to bet on domestic over foreign stocks (Dimmock et al., 2016; French and Poterba, 1991) and on weather events in their home country rather than abroad (Abdellaoui et al., 2020, Chew et al., 2012, de Lara Resende and Wu, 2010). In our experiment, subjects may have felt more competent or knowledgeable in their judgment about a fellow subject's trustworthiness or her snack preferences, but ignorant about the Ellsberg-like mechanism. Apparently, people feel a special aversion toward artificially created Ellsberg-like ambiguity that is not representative of ambiguity in general.

Whereas our subjects do not display aversion toward social ambiguity, they still violate ambiguity neutrality. The violation is cognitive rather than motivational. There is significant likelihood a-insensitivity for all-social and non-socialambiguities, but a-insensitivity is stronger for betrayal ambiguity. Whereas classical theories as used in BZ's analysis have focused on motivational components, our findings add to the growing empirical evidence that insensitivity is an important component. For example, Costa-Gomes and Weizsäcker (2008, p. 731) found that subjects in their experimental games were not responsive to their subjective beliefs, and wrote: "The subjects' play of the games appears to be naïve, as if they expected their opponents to choose actions randomly. But in the belief statement task they calibrate better, predicting roughly that their opponents respond to uniform beliefs." This finding can well be explained by a-insensitivity. A-insensitivity also has implications for the interaction between betrayal aversion and perceived likelihood of betrayal. It implies that peo- 
ple prefer betrayal ambiguity over nature ambiguity (betrayal-seeking) for small likelihoods of winning but reverse these preferences for larger likelihoods of winning.

Our findings confirm those of Fetchenhauer and Dunning (2012). They found no betrayal aversion, using stimuli that avoided ambiguity and genuinely involved only risk. Houser et al. (2010) similarly found no difference between human betrayal decisions or random computer decisions. Our experiment can be taken as the extension of these results to ambiguity. Betrayal aversion has been studied in several other papers and different contexts (see Aimone and Houser, 2013 and its references) and the potential role of ambiguity attitudes there remains a topic for future research.

Our separation between social and nature ambiguity should be distinguished from the separation between ambiguity experiments with and without suspicion. In the latter, experimenters have the possibility to rig urns to reduce subjects' earnings. Suspicion does not play any role in our experiment. In the nature experiment, for instance, subjects gamble on or against all events. The experimenters have no interest in making some events more or less likely than others. The Prince incentive system further rules out any suspicion.

It can be argued that our nature treatment is also partly social because human beings (experimenters) designed the experiment with marked cards. However, this process was random, and the experimenters did not have any deliberate interest in marking cards one way or the other. In the social treatment, human beings had interests and decided willfully. We acknowledge that our nature treatment did not completely rule out human intervention, but only reduced it relative to the social treatment. It is difficult to completely rule out any human influence in whichever situation we face in life, and especially in tasks organized by experimenters.

For neuro-studies into the relations and differences between individual and strategic uncertainties and risks, see Nagel et al. (2018) and their references. They focus on level-k thinking, which is typical of strategic uncertainty as opposed to social or nature uncertainty. Here, again, separating out a non-strategic social component will be of interest.

The absence of a difference between non-strategic and strategic social behavior that we found is, of course, typical of the betrayal aversion that we studied and will not hold in general. For example, Chierchia et al. (2018) found that an increase of strategic complexity from stag hunt to entry games makes a difference. This shows that strategic components do add effects to mere social components. Those authors considered the role of ambiguity attitude, measured through a separate traditional Ellsberg urn experiment. Their design did not aim to control for variations in beliefs in success in the various ambiguous game situations. In particular, they provided theoretical results showing that even the sure outcomes and certainty equivalents offered to particular level-k players affected the beliefs and behaviors of those players in the games they played. This motivated our design of matching probabilities that, to the contrary, did not affect beliefs or behaviors in the games themselves so that we could control for them.

Bohnet et al. (2008 p. 295) gave a psychological explanation for their finding of betrayal aversion: "If trust is violated, she [the betrayed player] may incur betrayal costs, a psychological loss above and quite apart from any material costs." A psychological explanation for the absence found in this and other studies can be that positive emotions about gaining due to trustworthiness neutralize the negative emotions about losing due to betrayal.

We have studied ambiguity about other decision makers only in individual-player strategic decisions. The effect of group decisions (as in cooperative games) on ambiguity attitudes is a different topic, outside the scope of this paper. See Keck et al. (2014) and Keller et al. (2007). Given the early stage of the techniques presented here, we do not make strong empirical claims. Primarily, we hope that future studies in game theory will use ambiguity theories and social ambiguity to gain further insights.

\section{Conclusion}

This paper has shown that ambiguity plays a bigger role in games and social interactions than previously thought. Using modern refined techniques, we can parse out different components of ambiguity attitudes and identify their impact on strategic behavior. In particular, we find that a new component plays a role: social ambiguity, concerning willful acts chosen by interested others (which may be in non-strategic settings).

We apply our new controls for ambiguity attitudes to shed new light on a strategic phenomenon: Bohnet et al.'s (2004, 2008) often discussed betrayal aversion. Our analysis leads to new insights that strongly deviate from traditional inferences. Contrary to earlier claims in the literature, ambiguity plays a central role in Bohnet et al.'s game. When controlling for social ambiguity, we find no betrayal aversion. Apparently, people do not especially fear social or betrayal uncertainties. Instead, preferences reveal a cognitive effect: people do not understand betrayal uncertainties well. Our results show the desirability to correct for various components of ambiguity attitudes, including the new social component, before drawing conclusions about strategic effects.

\section{Appendix A. Ambiguity attitudes in MAP measurements}

This appendix shows that BZ's MAP findings may be due to nonneutral ambiguity attitudes without any betrayal aversion involved. As in BZ, we consider Fig. 1 without the between move. We assume that there is no betrayal aversion. Thus, there is no negative utility of having been betrayed, and the utility of outcomes is fixed. We do assume nonneutral attitudes towards ambiguity. 
For simplicity, we assume that the subject maximizes expected utility under risk, with $U(8,22)=0, U(15,15)=1$, and $U(10,10)=0.245$. This gives the risky preferences of Fig. $2 \mathrm{~b}$. BZ, therefore, predict $M A P=0.245$, or 0.25 if rounded, irrespective of what the ambiguity attitude is.

To model ambiguity attitudes, we use Schmeidler's (1989) rank-dependent utility (RDU), also known as Choquet expected utility, which uses a nonadditive event weighting function $W$ instead of Savage's (1954) additive subjective probability. As in Abdellaoui et al.'s (2011) source method, we consider the case where $W$ is of the form $w_{A}(P()$.$) . We call P$ values a(mbiguity)-neutral beliefs. They could be interpreted as the weights and beliefs of an ambiguity-neutral twin of the decision maker. The strictly increasing nonlinear $w_{A}$, the source function, captures ambiguity attitudes. Ambiguity attitudes as in Ellsberg's paradoxes can be modeled because $w_{A}$ for ambiguity is different than the weighting function for risk-which is linear under our assumption of EU. Probabilistic sophistication then holds "locally" within the source of the ambiguous events, but not "globally" if we join them with the risky events.

As explained before, we use a "forward" evaluation as in Fig. 3. In RDU, the act generated by a choice of MAP is evaluated by

$$
R D U=w_{A}(P(15,15)) \times 1+\left(w_{A}(P(15,15)+P(10,10))-w_{A}(P(15,15))\right) \times 0.245,
$$

where $P(15,15)$ is the probability of receiving the best outcome with utility 1 and $P(10,10)$ is the probability of receiving the middle outcome with utility 0.245 given the chosen MAP. We suppress the worst outcome because its utility is 0 . The MAP with the maximal RDU value is chosen.

For $w_{A}$, we use Prelec's (1998) popular compound invariance family

$$
w(p)=\left(\exp \left(-(-\ln (p))^{\alpha}\right)\right)^{\beta} .
$$

It is well suited to capture ambiguity attitudes. Parameter $\beta$ captures the ambiguity aversion component with aversion $(\beta>1)$, indifference/neutrality $(\beta=1)$, or seeking $(\beta<1)$. This parameter plays a role similar as our index $b$ above and is commonly put central in normatively oriented theoretical studies on ambiguity. Parameter $\alpha$ captures the insensitivity component with insensitivity $(\alpha<1)$, neutrality $(\alpha=1)$, or oversensitivity $(\alpha>1)$. It is similar to our index $a$. The power family results as the subfamily with a fixed $\alpha=1$. In general, $w_{A}$ may depend on the source of uncertainty. Based on BZ's claim of betrayal aversion, one might, a priori, expect source preference (smaller $\beta$ ) for the risky dictator game over the trust game. This could be taken as an alternative way to model betrayal aversion, alternative to BZ's modeling through utility functions. However, to demonstrate that ambiguity attitudes can generate their observations without any aversion/preference component, we assume the same $w_{A}$ for both the risky dictator game and the trust game here.

We next discuss assumptions about beliefs for the two treatments of BZ considered here: the trust game treatment and the risky dictator treatment. For the first treatment, we assume that the subject received a signal claiming $p^{*}=0.29$. ${ }^{13}$ Such a signal could be interpreted as the subject's extrapolation from her past experience in social interactions. She believes that the signal is correct with probability 0.5 . Conditional on the signal being incorrect, she assigns uniform prior probabilities $1 / 101$ to all $p^{*}$. Hence, $\pi\left(p^{*}=0.29\right)=0.5+0.5 / 101$ and the remaining probability mass is divided uniformly over all other $p^{*}$. Probabilities of receiving each outcome further depend on the choice of MAP. For instance, for the act $M A P=0.25$, $P(10,10)=\pi\left(p^{*}<0.25\right)=0.124, P(15,15)=\sum_{i=25}^{100} \pi\left(p^{*}=\frac{i}{100}\right) \times \frac{i}{100}=0.380$, and $P(8,22)=0.496$. We do maintain the assumption of reduction of compound lotteries here. In Schmeidler's RDU, ambiguity attitudes are modeled through nonadditive weighting and reduction of compound lotteries need not be abandoned.

For the second treatment, the risky dictator game treatment, the subject has little information about $p^{*}$. We assume that the subject then considers all $p^{*}$ equally probable, assigning prior probability $\pi\left(p^{*}\right)=1 / 101$ to each. This belief, with average $p^{*}=0.5$, is relatively more optimistic than the belief in the trust game.

Table A.1 presents a numerical analysis with different parameter values of the weighting function. It shows that for the most common combinations of parameters, the optimal MAP in the trust game is larger than that in the risky dictator game. This gives rise to empirical patterns consistent with BZ's findings without there being any betrayal aversion.

The first rows have $\alpha=1$, so that insensitivity plays no role. With $\beta=2$ we then get convex functions $w_{A}$ and $W$, and ambiguity aversion. This case has been almost exclusively considered in theoretical studies and in game theory. With $\beta=1$ we get SEU, and with $\beta=\frac{1}{2}$ ambiguity seeking. The parameters in the penultimate row are the most common ones found empirically for risky probability weighting (Wakker, 2010 p. 207). Note, however, that our $w_{A}$ is of a different kind, capturing ambiguity attitudes rather than risk attitudes. We nevertheless present calculations for these values. Finally, we consider an extreme deviation from ambiguity neutrality, with $\alpha$ yet smaller and $\beta$ yet larger.

BZ claimed that ambiguity attitudes play no role, i.e.,

BZ's Claim: $M A P_{t}=p_{t}=p_{r}=M A P_{r}$ in all cases.

$M A P_{t}=M A P_{r}$ would imply that ambiguity cannot replace betrayal aversion, whereas $M A P_{t}>M A P_{r}$ implies that it can. BZ's claimed equalities hold true in the third row, i.e., under SEU, which BZ assumed implicitly. However, in all other rows

\footnotetext{
13 Bohnet et al. (2008) found $p=0.29$ for their two largest countries: China and the US. The signal could be that the subject knows about this finding from these two countries, and thinks that her opponent comes from these countries with probability 0.5 .
} 
Table A.1

Optimal MAPs by ambiguity attitudes without betrayal aversion.

\begin{tabular}{|c|c|c|c|c|}
\hline \multirow[t]{2}{*}{$w_{A}$} & \multicolumn{2}{|l|}{ trust } & \multicolumn{2}{|l|}{ risky dictator } \\
\hline & BZ predict & optimal & BZ predict & optimal \\
\hline$\alpha=1 ; \beta=2$ & $\begin{array}{l}p_{t}=0.25 \\
R D U=0.171\end{array}$ & $\begin{array}{l}M A P_{t}=0.73 \\
R D U=0.247\end{array}$ & $\begin{array}{l}p_{r}=0.25 \\
R D U=0.293\end{array}$ & $\begin{array}{l}M A P_{r}=0.39 \\
R D U=0.299\end{array}$ \\
\hline$\alpha=1 ; \beta=1$ & $\begin{array}{l}p_{t}=0.25 \\
R D U=0.410\end{array}$ & $\begin{array}{l}M A P_{t}=0.25 \\
R D U=0.410\end{array}$ & $\begin{array}{l}p_{r}=0.25 \\
R D U=0.531\end{array}$ & $\begin{array}{l}M A P_{r}=0.25 \\
R D U=0.531\end{array}$ \\
\hline$\alpha=1 ; \beta=1 / 2$ & $\begin{array}{l}p_{t}=0.25 \\
R D U=0.6394\end{array}$ & $\begin{array}{l}M A P_{t}=0.23 \\
R D U=0.6395\end{array}$ & $\begin{array}{l}p_{r}=0.25 \\
R D U=0.7253\end{array}$ & $\begin{array}{l}M A P_{r}=0.22 \\
R D U=0.7258\end{array}$ \\
\hline$\alpha=0.65 ; \beta=1.0467$ & $\begin{array}{l}p_{t}=0.25 \\
R D U=0.379\end{array}$ & $\begin{array}{l}M A P_{t}=0.40 \\
R D U=0.383\end{array}$ & $\begin{array}{l}p_{r}=0.25 \\
R D U=0.463\end{array}$ & $\begin{array}{l}M A P_{r}=0.31 \\
R D U=0.464\end{array}$ \\
\hline$\alpha=0.30 ; \beta=1.2$ & $\begin{array}{l}p_{t}=0.25 \\
R D U=0.314\end{array}$ & $\begin{array}{l}M A P_{t}=1 \\
R D U=0.349\end{array}$ & $\begin{array}{l}p_{r}=0.25 \\
R D U=0.354\end{array}$ & $\begin{array}{l}M A P_{r}=1 \\
R D U=0.358\end{array}$ \\
\hline
\end{tabular}

The first (left) column specifies the ambiguity attitude through Eq. (A.2). The second and third columns concern the trust game, with first BZ's predicted optimal MAP, being $p_{t}$, and then the real optimal MAP, MAP ${ }_{t}$. The fourth and fifth column similarly concern the risky dictator game, now using subscripts $\mathrm{r}$.

there is no ambiguity neutrality and the claimed equalities are violated. We mostly find $M A P_{t}>M A P_{r}$, so that ambiguity (without betrayal aversion) can indeed accommodate BZ's data. The implications are close to the equalities of SEU under ambiguity seeking because it tends to neutralize the unfavorable beliefs (due to the unfavorable signal) in the trust game. In the last row, because of the extreme insensitivity, there is extreme overweighting near $P=0$ and, which is relevant for us, there is extreme underweighting near $P=1$. The latter reinforces the certainty effect (here due to ambiguity) so much that subjects never enter the trust game. They have an extreme "global" dislike to ambiguity in the right branch of Fig. 3 and just always go left.

The assumption of EU for risk in this example can be relaxed by introducing a nonlinear probability weighting function $w$ for risk. Then $W(E)=w_{A}\left(w(P(E))\right.$, with $w_{A}$ again capturing ambiguity attitudes. It leads to similar results as above.

Many other examples can be constructed with different ambiguity attitudes in the two treatments or different nonEU evaluations of the dynamic optimization problems. There are many attitudinal components in nonEU besides betrayal aversion. In general, no clear conclusions can be drawn from the complex MAP measurements. To find out what drives MAP experiments, further measurements would be needed, concerning ambiguity attitudes, and perceptions and attitudes towards dynamic optimization.

Quercia (2016) replicated the experiment of BZ but made three simplifications to the MAP design. First, she derived MAPs indirectly from choice lists, second, she expressed probabilities in terms of frequencies, and, third, she improved the instructions. These improvements led to a better understanding of the MAP elicitation procedure. However, they do not resolve the problems discussed here. Not surprisingly, they did not lead to different findings than BZ's.

\section{Appendix B. Supplementary material}

Supplementary material related to this article can be found online at https://doi.org/10.1016/j.geb.2020.07.007.

\section{References}

Abdellaoui, Mohammed, Baillon, Aurélien, Placido, Laetitia, Wakker, Peter P., 2011. The rich domain of uncertainty: source functions and their experimental implementation. Am. Econ. Rev. 101, 695-723.

Abdellaoui, Mohammed, Bleichrodt, Han, Kemel, Emmanuel, L'Haridon, Olivier, 2020. Measuring beliefs under ambiguity. Oper. Res. Forthcoming.

Aimone, Jason A., Houser, Daniel, 2013. Harnessing the benefits of betrayal aversion. J. Econ. Behav. Organ. 89, 1-8.

Anscombe, Frank J., Aumann, Robert J., 1963. A definition of subjective probability. Ann. Math. Stat. 34, 199-205.

Aumann, Robert J., Drèze, Jacques H., 2009. Assessing strategic risk. Am. Econ. J. Microecon. 1, 1-16.

Bade, Sophie, 2015. Randomization devices and the elicitation of ambiguity-averse preferences. J. Econ. Theory 159, 221-235.

Baillon, Aurélien, Huang, Zhenxing, Selim, Asli, Wakker, Peter P., 2018. Measuring ambiguity attitudes for all (natural) events. Econometrica 86, 1839-1858.

Baltussen, Guido, Post, Thierry, van den Assem, Martijn J., Wakker, Peter P., 2012. Random incentive systems in a dynamic choice experiment. Exp. Econ. 15, 418-443.

Bardsley, Nicholas, Cubitt, Robin P., Loomes, Graham, Moffat, Peter, Starmer, Chris, Sugden, Robert, 2010. Experimental Economics; Rethinking the Rules. Princeton University Press, Princeton, NJ.

Battigalli, Pierpaolo, Catonini, Emiliano, Lanzani, Giacomo, Marinacci, Massimo, 2019. Ambiguity attitudes and self-confirming equilibrium in sequential games. Games Econ. Behav. 115, 1-29.

Bohnet, Iris, Greig, Fiona, Herrmann, Benedikt, Zeckhauser, Richard, 2008. Betrayal aversion: evidence from Brazil, China, Oman, Switzerland, Turkey, and the United States. Am. Econ. Rev. 98, 294-310.

Bohnet, Iris, Zeckhauser, Richard, 2004. Trust, risk and betrayal. J. Econ. Behav. Organ. 55, 467-484.

Bolton, Gary E., Feldhaus, Christoph, Ockenfels, Axel, 2016. Social interaction promotes risk taking in a stag hunt game. Ger. Econ. Rev. 17, 409-423.

Bommier, Antoine, 2017. A dual approach to ambiguity aversion. J. Math. Econ. 71, 104-118.

Brosig, Jeanette, Weimann, Joachim, Yang, Chun-Lei, 2003. The hot versus cold effect in a simple bargaining experiment. Exp. Econ. 6, 75-90.

Burks, Arthur W., 1977. Chance, Cause, Reason (An Inquiry into the Nature of Scientific Evidence). The University of Chicago Press, Chicago. 
Calford, Evan M., 2020. Uncertainty aversion in game theory: experimental evidence. J. Econ. Behav. Organ. 176, 720-734.

Cerreia-Vioglio, Simone, Ghirardato, Paolo, Maccheroni, Fabio, Marinacci, Massimo, Siniscalchi, Marciano, 2011. Rational preferences under ambiguity. Econ. Theory 48, 341-375.

Chark, Robin, Chew, Soo Hong, 2015. A neuroimaging study of preference for strategic uncertainty. J. Risk Uncertain. 50, 209-227.

Chew, Soo Hong, Ebstein, Richard P., Zhong, Songfa, 2012. Ambiguity aversion and familiarity bias: evidence from behavioral and gene association studies. J. Risk Uncertain. 44, 1-18.

Chew, Soo Hong, Sagi, Jacob S., 2008. Small worlds: modeling attitudes toward sources of uncertainty. J. Econ. Theory 139, 1-24.

Chierchia, Gabriele, Nagel, Rosemarie, Coricelli, Giorgio, 2018. Betting 'on nature' or 'betting on others': anti-coordination induces uniquely high levels of entropy. Sci. Rep. 8, 3514. https://doi.org/10.1038/s41598-018-21962-1.

Cohen, Michèle, Gilboa, Itzhak, Jaffray, Jean-Yves, Schmeidler, David, 2000. An experimental study of updating ambiguous beliefs. Risk Decis. Policy 5, 123-133.

Costa-Gomes, Miguel, Huck, Steffen, Weizsäcker, Georg, 2014. Beliefs and actions in the trust game: creating instrumental variables to estimate the causal effect. Games Econ. Behav. 88, 298-309.

Costa-Gomes, Miguel, Weizsäcker, Georg, 2008. Stated beliefs and play in normal-form games. Rev. Econ. Stud. 75, 729-762.

Cox, James C., Sadiraj, Vjollca, Schmidt, Ulrich, 2015. Paradoxes and mechanisms for choice under risk. Exp. Econ. 18, 215-250.

Cubitt, Robin P., Starmer, Chris, Sugden, Robert, 1998. Dynamic choice and the common ratio effect: an experimental investigation. Econ. J. 108, 1362-1380.

de Lara Resende, José G., Wu, George, 2010. Competence effects for choices involving gains and losses. J. Risk Uncertain. 40, 109-132.

Di Mauro, Carmela, Castro, Massimo Finocchiaro, 2011. Kindness, confusion, or ... ambiguity? Exp. Econ. 14, 611-633.

Dimmock, Stephen G., Kouwenberg, Roy, Wakker, Peter P., 2016. Ambiguity attitudes in a large representative sample. Manag. Sci. 62, $1363-1380$.

Dominiak, Adam, Duersch, Peter, 2019. Interactive Ellsberg task: an experiment. J. Econ. Behav. Organ. 161, 145-157.

Dominiak, Adam, Duersch, Peter, Lefort, Jean-Philippe, 2012. A dynamic Ellsberg urn experiment. Games Econ. Behav. 75, 625-638.

Eichberger, Jürgen, Kelsey, David, 2011. Are the treasures of game theory ambiguous? Econ. Theory 48, 313-393.

Ellis, Andrew, 2018. On dynamic consistency in ambiguous games. Games Econ. Behav. 111, 241-249.

Ellsberg, Daniel, 1961. Risk, ambiguity and the Savage axioms. Q. J. Econ. 75, 643-669.

Evren, Özgür, 2019. Recursive non-expected utility: connecting ambiguity attitudes to risk preferences and the level of ambiguity. Games Econ. Behav. 114, 285-307.

Fetchenhauer, Detlef, Dunning, David, 2012. Betrayal aversion versus principled trustfulness: how to explain risk avoidance and risky choices in trust games.

J. Econ. Behav. Organ. 81, 534-541.

Fox, Craig R., Weber, Martin, 2002. Ambiguity aversion, comparative ignorance, and decision context. Organ. Behav. Hum. Decis. Process. 88, 476-498.

French, Kenneth R., Poterba, James M., 1991. Investor diversification and international equity markets. Am. Econ. Rev. 81, 222-226.

Gayer, Gabrielle, 2010. Perception of probabilities in situations of risk; a case based approach. Games Econ. Behav. 68, 130-143.

Ghirardato, Paolo, 2002. Revisiting Savage in a conditional world. Econ. Theory 20, 83-92.

Gilboa, Itzhak, Schmeidler, David, 1989. Maxmin expected utility with a non-unique prior. J. Math. Econ. 18, 141-153.

Gilboa, Itzhak, Schmeidler, David, 2003. A derivation of expected utility maximization in the context of a game. Games Econ. Behav. 44, 184-194.

Gonzalez, Richard, Wu, George, 1999. On the shape of the probability weighting function. Cogn. Psychol. 38, 129-166.

Güth, Werner, Huck, Steffen, Müller, Wieland, 2001. The relevance of equal splits in ultimatum games. Games Econ. Behav. 37, 161-169.

Halevy, Yoram, 2015. Time consistency: stationarity and time invariance. Econometrica 83, 335-352.

Hammond, Peter J., 1988. Consequentialist foundations for expected utility. Theory Decis. 25, 25-78.

Harsanyi, John C., 1982. Subjective probability and the theory of games: comments on Kadane and Larkey's paper. Manag. Sci. 28, 120-125.

Heath, Chip, Tversky, Amos, 1991. Preference and belief: ambiguity and competence in choice under uncertainty. J. Risk Uncertain. 4, 5-28.

Heinemann, Frank, Nagel, Rosemarie, Ockenfels, Peter, 2009. Measuring strategic uncertainty in coordination games. Rev. Econ. Stud. 76, 181-221.

Holt, Charles A., 1986. Preference reversals and the independence axiom. Am. Econ. Rev. 76, 508-513.

Houser, Daniel, Schunk, Daniel, Winter, Joachim, 2010. Distinguishing trust from risk: an anatomy of the investment game. J. Econ. Behav. Organ. 74, 72-81. Ivanov, Asen, 2011. Attitudes to ambiguity in one-shot normal-form games: an experimental study. Games Econ. Behav. 71, 366-394.

Johnson, Cathleen, Baillon, Aurélien, Bleichrodt, Han, Li, Zhihua, van Dolder, Dennie, Wakker, Peter P., 2020. Prince: an Improved Method for Measuring

Incentivized Preferences. Working paper.

Kahneman, Daniel, Tversky, Amos, 1979. Prospect theory: an analysis of decision under risk. Econometrica 47, 263-291.

Karni, Edi, Safra, Zvi, 1987. Preference reversal and the observability of preferences by experimental methods. Econometrica 55, 675-685.

Keck, Steffen, Diecidue, Enrico, Budescu, David V., 2014. Group decisions under ambiguity: convergence to neutrality. J. Econ. Behav. Organ. $103,60-71$.

Keller, L. Robin, Sarin, Rakesh K., Sounderpandian, Jayavel, 2007. An examination of ambiguity aversion: are two heads better than one? Judgm. Decis.

Mak. 2, 390-397.

Kellner, Christian, le Quement, Mark T., 2017. Modes of ambiguous communication. Games Econ. Behav. 104, 271-292.

Kelsey, David, le Roux, Sara, 2015. An experimental study on the effect of ambiguity in a coordination game. Theory Decis. 79, 667-688.

Kelsey, David, le Roux, Sara, 2018. Strategic ambiguity and decision-making: an experimental study. Theory Decis. 84, 387-404.

Kets, Willemien, Sandroni, Alvaro, 2019. A belief-based theory of homophily. Games Econ. Behav. 115, 410-435.

Klibanoff, Peter, Marinacci, Massimo, Mukerji, Sujoy, 2005. A smooth model of decision making under ambiguity. Econometrica 73, $1849-1892$.

Kugler, Tamar, Connolly, Terry, Ordóñez, Lisa D., 2012. Emotion, decision, and risk: betting on gambles versus betting on people. J. Behav. Decis. Mak. 25, 123-134.

l'Haridon, Olivier, Vieider, Ferdinand, Aycinena, Diego, Bandur, Augustinus, Belianin, Alexis, Cingl, Lubomir, Kothiyal, Amit, Martinsson, Peter, 2018. Off the

charts: massive unexplained heterogeneity in a global study of ambiguity attitudes. Rev. Econ. Stat. 100, 664-677.

Li, Chen, Turmunkh, Uyanga, Wakker, Peter P., 2019. Trust as a decision under ambiguity. Exp. Econ. 22, 51-75.

Machina, Mark J., 1989. Dynamic consistency and non-expected utility models of choice under uncertainty. J. Econ. Lit. 27, $1622-1688$.

Machina, Mark J., 2014. Ambiguity aversion with three or more outcomes. Am. Econ. Rev. 104, 3814-3840.

Marinacci, Massimo, 2015. Model uncertainty. J. Eur. Econ. Assoc. 13, 1022-1100.

McClennen, Edward F., 1990. Rationality and Dynamic Choice: Foundational Explorations. Cambridge University Press, Cambridge.

Nagel, Rosemarie, Brovelli, Andrea, Heinemann, Frank, Coricelli, Giorgio, 2018. Neural mechanisms mediating degrees of strategic uncertainty. Soc. Cogn.

Affect. Neurosci. 13, 52-62.

Perea, Andrés, 2012. Epistemic Game Theory: Reasoning and Choice. Cambridge University Press, New York.

Prelec, Drazen, 1998. The probability weighting function. Econometrica 66, 497-527.

Quercia, Simone, 2016. Eliciting and measuring betrayal aversion using the BDM mechanism. J. Econ. Sci. Assoc. 2, 48-59.

Savage, Leonard J., 1954. The Foundations of Statistics. Wiley, New York, 2nd edn. Dover Publications, New York, 1972.

Schmeidler, David, 1989. Subjective probability and expected utility without additivity. Econometrica 57, 571-587.

Schneeweiss, Hans, 1973. The Ellsberg paradox from the point of view of game theory. Inference Decis. 1, 65-78.

Schneider, Florian, Schonger, Martin, 2018. An experimental test of the Anscombe-Aumann monotonicity axiom. Manag. Sci. 65, 1667-1677. 
Skiadas, Costis, 2013. Scale-invariant uncertainty-averse preferences and source-dependent constant relative risk aversion. Theor. Econ. 8, 59-93.

Sugden, Robert, 1991. Rational choice: a survey of contributions from economics and philosophy. Econ. J. 101, 751-785.

Trautmann, Stefan T., van de Kuilen, Gijs, 2015. Ambiguity attitudes. In: Keren, Gideon, Wu, George (Eds.), The Wiley Blackwell Handbook of Judgment and Decision Making. Blackwell, Oxford, UK, pp. 89-116.

Veblen, Thorstein, 1909. The limitations of marginal utility. J. Polit. Econ. 17, 620-636.

von Neumann, John, Morgenstern, Oskar, 1944. Theory of Games and Economic Behavior. Princeton University Press, Princeton NJ. $1947,1953$.

Wakker, Peter P., 2010. Prospect Theory: For Risk and Ambiguity. Cambridge University Press, Cambridge, UK. 